\title{
PENINGKATAN KEMAMPUAN BERPIKIR KRITIS MAHASISWA MELALUI MODEL PEMBELAJARAN PROBLEM BASED INSTRUCTION (PBI) PADA MATA KULIAH FILSAFAT SAINS
}

\author{
Irnin Agustina Dwi Astuti \\ Program Studi Pendidikan Fisika, Fakultas Teknik dan MIPA, \\ Universitas Indraprasta PGRI \\ Email: irnin.agustina@gmail.com
}

\begin{abstract}
Critical thinking skills the students of Physical Education remains low. It is caused by several factors, including the learning process is not optimal. This study aims to determine the increase in critical thinking skills by learning model Problem Based Instruction (PBI). The method used is a classroom action research that includes planning, implementation, observation, and reflection. Data collections are done by observation, questionnaires, documentation, field notes and tests. Forms of data analysis used qualitative analysis. It can be concluded that the implementation of learning with Problem Based Instruction learning model can improve the critical thinking skills students in Philosophy of Science. This is evidenced by the increase in the average percentage of critical thinking skills of each cycle. In the first cycle, the average critical thinking skills students are $66.87 \%$. In the second cycle into $80.19 \%$ or an increase of $13.32 \%$. Thus the average percentage of critical thinking skills students has exceeded predetermined success criteria with the category is "very critical".
\end{abstract}

Keywords: Critical thinking, Problem Based Instruction, learning Model.

\section{PENDAHULUAN}

Mata kuliah Filsafat Sains mempunyai bobot 2 sks dan diajarkan untuk mahasiswa Pendidikan Fisika semester tiga. Filsafat sains membahas ilmu pengetahuan yang menyelidiki segala sesuatu yang ada secara mendalam dengan menggunakan akal sampai pada hakikatnya. Filsafat bukan mempersoalkan gejala-gejala atau fenomena, tetapi yang dicari adalah hakikat dari suatu masalah.

Menurut Immanuel Kant dalam Tafsir (2012:22), filsafat adalah ilmu 
(pengetahuan) yang menjadi pokok pangkal dari segala pengetahuan, yang didalamnya tercakup masalah epistemologi (filsafat pengetahuan) yang menjawab persoalan apa yang dapat kita ketahui.

Setelah observasi dikelas, dalam mempelajari Filsafat Sains terlihat mahasiswa sulit mengemukakan ideide kritis dan takut untuk berpendapat dalam memecahkan masalah. Hal itu membuat hasil belajar mahasiswa rendah. Rendahnya hasil belajar mahasiswa mungkin terjadi karena penyajiannya lebih sering menggunakan metode ceramah yang membuat mahasiswa menjadi jenuh dan bosan, sehingga kurang menciptakan sikap kritis mahasiswa dalam memecahkan masalah.

Dalam mempelajari mata kuliah Filsafat Sains seharusnya mahasiswa bisa berpikir secara luas konsep filsafat karena merupakan dasar pengetahuan yang berkaitan dengan ilmu-ilmu nyata. Mahasiswa bisa lebih kritis dalam menanggapi suatu masalah, sehingga mahasiswa bisa memahami materi dengan baik. Kenyataan dalam lapangan mahasiswa hanya menghafal konsep dan kurang mampu menggunakan konsep itu jika menemui masalah dalam kehidupan nyata.

Berpikir kritis adalah sebuah proses terorganisasi yang memungkinkan siswa mengevaluasi bukti, asumsi, logika, dan bahasa yang mendasari pernyataan orang lain. Tujuan dari berpikir kritis adalah untuk mencapai pemahaman yang mendalam (Johnson, 2011:65). Setiap orang memiliki kemampuan untuk menjadi seorang pemikir kritis yang andal. Setiap orang dapat belajar untuk berpikir dengan kritis karena otak manusia secara konstan berusaha memahami pengalaman (Johnson, 2011:65). Berdasarkan pernyataan tersebut, maka diketahui bahwa kemampuan berpikir kritis seseorang dapat dilatih.

Untuk mengembangkan kemampuan berpikir kritis, diperlukan suatu desain pembelajaran yang dapat mengembangkan potensi otak. Model pembelajaran berbasis masalah merupakan suatu model pembelajaran yang didasarkan pada banyaknya permasalahan yang membutuhkan penyelidikan autentik, yakni penyelidikan yang membutuhkan 
Irnin Agustina - Peningkatan Kemampuan Berpikir...

penyelesaian nyata dari permasalahan yang nyata. Model pembelajaran yang cocok digunakan dalam mengatasi masalah tersebut yaitu model pembelajaran Problem Based Instruction $\quad$ (PBI). Model pembelajaran PBI yaitu suatu model pembelajaran yang didasarkan pada prinsip menggunakan masalah sebagai titik awal akuisisi dan integrasi pengetahuan baru (AlTabany, 2014:70). Tujuan dari penelitian ini untuk mengetahui peningkatan kemampuan berpikir kritis mahasiswa melalui model pembelajaran $P B I$.

\section{METODE}

Subjek penelitian ini adalah mahasiswa Program Studi Pendidikan Fisika menempuh mata kuliah Filsafat Sains tahun akademik 2015/2016. Penelitian ini merupakan Penelitian Tindakan Kelas (PTK). PTK adalah penelitian tindakan yang dilaksanakan di dalam kelas ketika pembelajaran berlangsung (Warso, 2013:3). Setiap siklusnya terdiri dari empat tahap yaitu perencanaan, tindakan, pengamatan dan refleksi. Penelitian ini dilaksanakan dengan dua siklus yang prosedur prcobaan dapat dilihat pada gambar 1 .

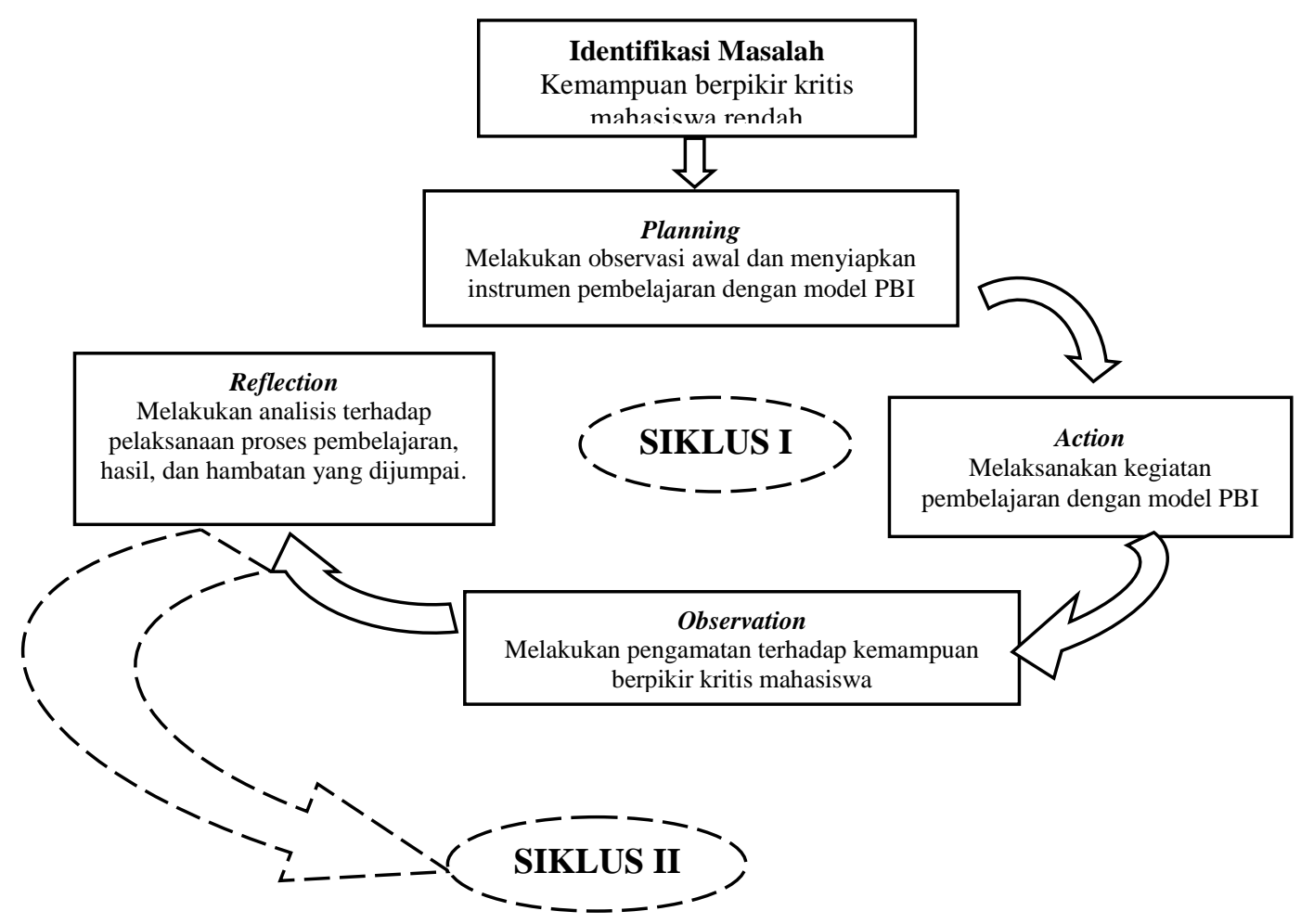

Gambar 1. Alur pelaksanaan PTK 
Pengambilan data dilakukan dengan metode observasi dan angket. Instrumen yang diberikan berupa lembar observasi untuk mengetahui kemampuan berpikir kritis mahasiswa dan aktivitas mahasiswa, serta lembar angket untuk mengetahui respon mahasiswa dalam pembelajaran di kelas. Tolok ukur keberhasilan pelaksanaan penelitian ini dapat dilihat dari hasil pengukuran ketrampilan proses yang cenderung semakin meningkat dan hasil belajar yang semakin baik.

\section{HASIL DAN PEMBAHASAN}

Pada siklus pertama dosen memberikan arahan dan tujuan pembelajaran terlebih dahulu dalam pelaksanaan model PBI. Pada siklus I, awalnya mahasiswa merasa sulit dan ragu-ragu menjawab pertanyaanpertanyaan dalam Lembar Kerja Mahasiswa (LKM). Dosen memberikan arahan agar pertanyaanpertanyaan dalam LKM dikerjakan secara urut sehingga dapat diperoleh jawaban yang benar. Dari satu kelompok hanya satu atau dua orang saja yang aktif dan berani dalam berpendapat. Dalam melakukan diskusi masih ada peran dosen yang mengarahkan dalam membimbing permasalahan. Jadi, campur tangan dosen masih ada pada siklus I. Hasil observasi siklus I dijadikan refleksi, yang kemudian dilakukan pembelajaran pada siklus II

Pelaksanaan pembelajaran Problem Based Instruction pada siklus II telah sesuai rencana. Mahasiswa sudah mulai terbiasa dengan model pembelajaran yang diterapkan dan pembiasaan berpikir kritis dalam memecahkan masalah di setiap pembelajaran, sehingga pada siklus II diskusi dapat lebih lancar dari siklus I. Mahasiswa lebih aktif dalam melakukan kegiatan penyelidikan dan dosen hanya sedikit memberikan bimbingan. Hasil kemampuan berpikir kritis mahasiswa disajikan pada Tabel 1.

Hasil siklus I ke siklus II mengalami peningkatan, seperti pada gambar 2. Pada siklus I rata-rata persentase kemampuan berpikir kritis mahasiswa $66,87 \%$, dan pada siklus II 80,19 \%. Peningkatan kemampuan berpikir kritis mahasiswa dari siklus I 
Irnin Agustina - Peningkatan Kemampuan Berpikir...

ke siklus II sebesar $13,32 \%$. Ini kritis dalam menghadapi suatu terlihat mahasiswa sudah mulai permasalahan.

terbiasa berpendapat dan berpikir

Tabel 1. Hasil kemampuan berpikir kritis

\begin{tabular}{clrc}
\hline \multirow{2}{*}{ No } & \multicolumn{1}{c}{ Komponen } & \multicolumn{2}{c}{ Rata-rata } \\
& & Siklus I & Siklus II \\
\hline 1. & Memfokuskan pertanyaan & 65,56 & 81,24 \\
2. & Menganilis argumen & 75,55 & 78,98 \\
3. & Bertanya jawab pertanyaan & 60,80 & 75,89 \\
4. & Mempertimbangkan & 65,72 & 77,65 \\
5. & kredibilitas & 68,42 & 82,35 \\
6. & Mengobservasi & 60,25 & 80,20 \\
7 & Membuat deduksi & 62,36 & 81,20 \\
8. & Membuat kesimpulan & 70,23 & 80,67 \\
9. & Mengidentifikasi asumsi & 71,23 & 79,30 \\
10. & Mengidentifikasi istilah & 67,87 & 81,80 \\
11 & Memutuskan suatu & 65,56 & 79,30 \\
& tindakan & & \\
12. & Berinteraksi dengan orang & 68,87 & 83,45 \\
\hline \multicolumn{2}{r}{ Rain } & 66,87 & 80,19 \\
\hline
\end{tabular}

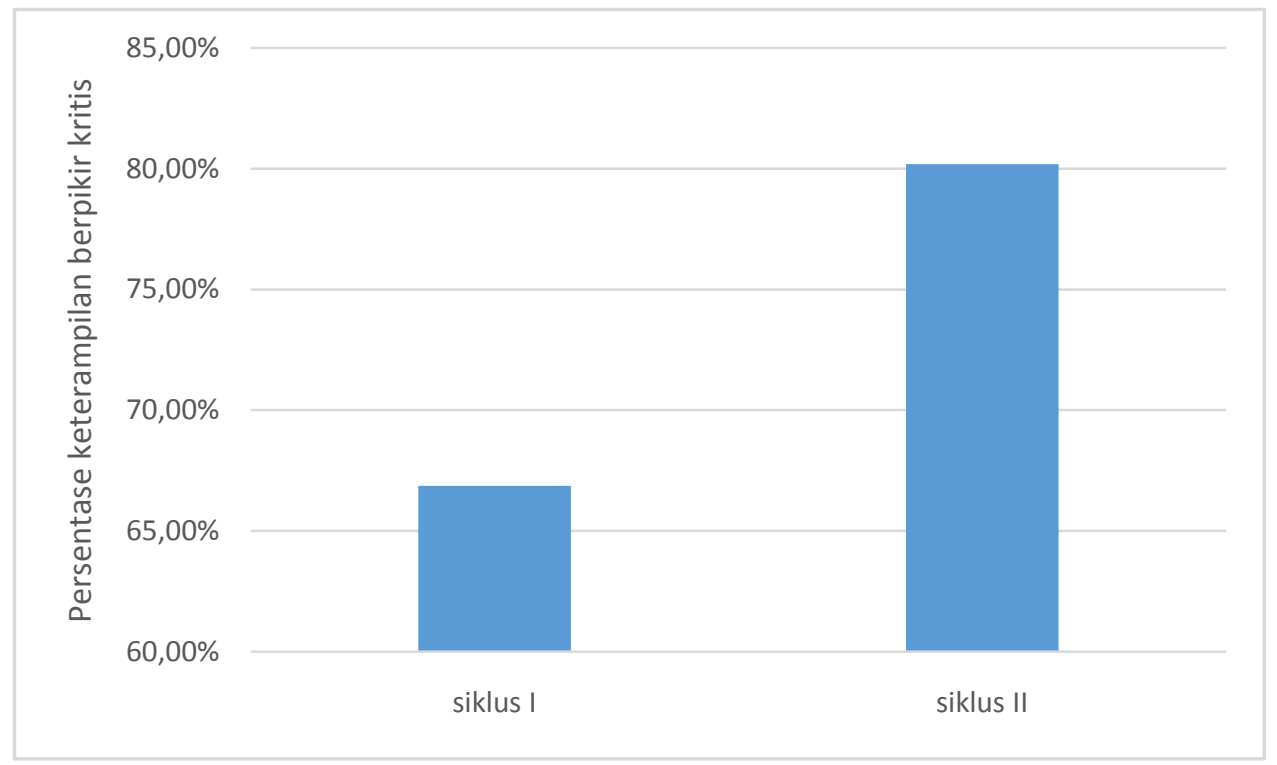

Gambar 2. Persentase kemampuan berpikir kritis mahasiswa 
Problem Based Instruction adalah suatu metode atau pendekatan pengajaran yang menggunakan masalah kondisi nyata sebagai suatu konteks bagi mahasiswa untuk belajar tentang cara berpikir kritis dan keterampilan pemecahan masalah, serta untuk memperoleh pengetahuan dan konsep yang essensial dari materi pelajaran (Nurhadi, 2004:109). Dosen berpartisipasi dalam membangun pemahaman mahasiswa. Partisipasi dosen hendaknya dibatasi pada peran fasilitator dan mitra belajar mahasiswa, misalnya merangsang dan menyajikan situasi berpikir untuk mahasiswa pada masalah autentik dari suatu materi melalui penerapan konsep dan fakta. Dengan dihadapkan pada kondisi belajar seperti ini, mahasiswa mempunyai kecenderungan untuk memberi arti pada masalah dan kejadian disekitarnya. Ini memberi indikasi pada kemampuan berpikir yang dimiliki mahasiswa. Keterkaitan kemampuan berpikir kritis dalam pembelajaran sains menurut Amarila (2014:564) adalah menghubungkan antara apa yang dipelajari dengan bagaimana memanfaatkannya dalam kehidupan sehari-hari, membantu siswa memecahkan masalah yang dihadapi, dan melatih siswa membuat keputusan yang tepat serta memacu siswa untuk selalu belajar.

Penelitian yang dilakukan oleh Kurniawati (2014:44) terdapat perbedaan penguasaan konsep dan kemampuan berpikir kritis fisika siswa yang menggunakan pembelajaran inkuiri terbimbing integrasi peer instruction, pembelajaran inkuiri terbimbing dan pembelajaran konvensional. Selanjutnya, penelitian yang dilakukan Hidayah (2013) tentang efektivitas model pembelajaran Problem Based Instruction (PBI) terhadap hasil belajar peserta didik SMAN 1 pemalang materi kelarutan dan hasil kali kelarutan menunjukkan bahwa model pembelajaran PBI efektif terhadap hasil belajar peserta didik. Hal ini terjadi karena melalui pemecahan masalah peserta didik akan terbiasa menemukan konsep sehingga akan memudahkan peserta didik dalam penguasaan terhadap 
materi dan pengerjaan soal materi kelarutan dan hasil kali kelarutan.

Penelitian yang relevan tersebut sejalan dengan penelitian ini yang membuktikan bahwa dengan model pembelajaran PBI dapat meningkatkan kemampuan berpikir kritis mahasiswa dengan kategori kemampuan berpikir kritis adalah "sangat kritis" karena rata-rata > 80,00 .

Peningkatan nilai rata-rata kemampuan berpikir kritis seiring dengan meningkatnya kemampuan mahasiswa dalam mengatasi suatu masalah. Mahasiswa sudah bisa mengeluarkan ide atau gagasan dan dan tidak takut lagi dalam berdebat maupun berpendapat. Pengetahuan mahasiswa tentang Filsafat Sains sudah mulai terbuka luas dan mempunyai gagasan yang matang dalam mendalami materi. Dari sejarah filsafat dan bidang keilmuan yang ada sudah bisa dijabarkan oleh mahasiswa dengan baik. Guru hanya berperan sebagai fasilitator. Dari hasil penelitian terlihat jelas bahwa pada dasarnya mahasiswa mempunyai potensi kemampuan berpikir kritis. Potensi ini sangat disayangkan jika tidak dapat dikembangkan dengan baik. Melalui penerapan model pembelajaran Problem Based Instruction, mahasiswa dapat mengembangkan kemampuan berpikir kritis.

\section{PENUTUP}

\section{Kesimpulan}

Pembelajaran dengan model Problem Based Instruction dapat meningkatkan kemampuan berpikir kritis mahasiswa. Diperoleh hasil rata-rata kemampuan berpikir kritis mahasiswa pada siklus I 66,87 \% dan siklus II 80,19\% dengan peningkatan sebesar 13,32 \%. Nilai rata-rata kemampuan berpikir kritis mahasiswa termasuk dalam kategori sangat kritis.

\section{Saran}

Untuk peneliti selanjutnya jika akan menggunakan model pembelajaran PBI harus menyusun rencana pembelajaran yang sistematis disertai Lembar Kerja Siswa agar mempermudah dalam pembelajaran. Alokasi waktu juga diperhatikan agar tidak kekurangan waktu dalam pelaksanaan pembelajaran. 


\section{DAFTAR PUSTAKA}

Al-Tabany, Trianto Ibnu Badar. 2014. Mendesain Model Pembelajaran Inovatif, Progresif, dan Kontekstual. Jakarta: Prenamedia Group.

Amarila, Raula Samsul. 2014. Pengembangan alat evaluasi kemampuan berpikir kritis siswa pada pembelajaran IPA terpadu model webbed tema lingkungan Unnes Science Education Journal ISSN 22526617.

Dwijananti. 2010. Pengembangan

Kemampuan Berpikir Kritis Mahasiswa Melalui Pembelajaran Problem Based Instruction Pada Mata Kuliah Fisika Lingkungan. Jurnal Pendidikan Fisika Indonesia 6 (2010) 108-114.

Hidayah, Nur. 2013. Efektivitas Model Pembelajaran Problem Based Instruction (PBI) terhadap hasil belajar siswa SMAN 1 Pemalang materi kelarutan dan hasil kali kelarutan. Skripsi, Jurusan Kimia, Fakultas Matematika dan Ilmu Pengetahuan Alam, Universitas Negeri Semarang.

Huda, Miftahul. 2015. Model-model Pengajaran dan Pembelajaran. Yogyakarta: Pustaka Pelajar.

Johnson, Elanie. 2009. Contextual Teaching \& Learning. Bandung: Mizan Learning Center (MLC).

Kurniawati. 2014. Pengaruh Pembelajaran Inkuiri Terbimbing Integrasi Peer Instruction Terhadap Penguasaan Konsep Dan Kemampuan Berpikir Kritis Siswa. Jurnal Pendidikan Fisika Indonesia 10 Universitas Negeri Semarang.
Nurhadi. 2004. Kurikulum 2004. Jakarta: Grasindo.

Tafsir, Ahmad. 2012. Filsafat Ilmu. Bandung: Remaja Rosdakarya.

Warso, Agus Wasisto Dwi Doso. 2013. Publikasi Ilmiah Penelitian Tindakan Kelas. Yogyakarta: Graha Cendekia. 